\title{
A ELABORAÇÃO DE MATERIAIS DIDÁTICOS PARA O ENSINO DE ESPANHOL COMO LÍNGUA ESTRANGEIRA NA PERSPECTIVA DOS MULTILETRAMENTOS
}

\section{THE DEVELOPMENT OF LEARNING MATERIALS FOR THE TEACHING OF SPANISH AS A FOREIGN LANGUAGE IN THE PERSPECTIVE OF MULTILITERACIES}

\author{
Gabriel Maciel Pereira* \\ Amanda Mendes** \\ Kelly Cristiane Henschel Pobbe de Carvalho***
}

\begin{abstract}
Resumo: O objetivo do presente artigo é discutir e compartilhar alguns resultados na elaboração de propostas didáticas para o ensino de espanhol/LE, com base na abordagem dos multiletramentos (ROJO e MOURA, 2012). Para o desenvolvimento deste estudo, utilizamos a metodologia qualitativa, de caráter interpretativista, nos moldes explicitados por Lüdke e André (1986), quando afirmam que neste tipo de pesquisa há ênfase no processo, preocupação em se retratar a perspectiva dos participantes, além de o ambiente natural constituir a fonte direta dos dados.

Palavras-chave: Propostas didáticas; Multiletramentos; Espanhol/LE.
\end{abstract}

ABSTRACT: The objective of this article is to discuss and share some results in the elaboration of didactic proposals for teaching Spanish / FL, based on the multiliteracies approach (ROJO and MOURA, 2012). For the development of this study, we will use the qualitative methodology, of an interpretative feature, as explained by Lüdke and André (1986), when they affirm that in this type of research there is an emphasis on the process, concern about portraying the perspective of the participants and the context is the direct source of the data.

Keywords: Didactic proposals; Multiliteracies; Spanish / Foreign Language.

\section{Introdução}

O presente artigo apresenta os resultados de um ano de desenvolvimento do projeto de pesquisa de iniciação científica, intitulado "A elaboração de materiais didáticos para o ensino de línguas na perspectiva dos multiletramentos", realizado no período de agosto de 2017 a agosto de 2018. Este trabalho se constituiu a partir das dificuldades que professores em formação inicial no curso de Letras apresentam ao

\footnotetext{
*Mestrando em "Lingüística Aplicada a la Enseñanza del Español como Lengua Extranjera" pela Universidad Nacional Europea del Atlántico, España (2019). Graduado em Letras Português - Espanhol pela Universidade Estadual Paulista "Júlio de Mesquita Filho" UNESP: Campus de Assis - Faculdade de Ciência de Letras. Email: gabrielmaciel95@hotmail.com

${ }^{* *}$ Mestre em Letras pela Universidade Estadual Paulista Júlio de Mesquita Filho - UNESP/Assis (2016) É professora de Língua Espanhola nas escolas CCAA/Assis e Languages/Assis. Email: amandamendes.unesp@ gmail.com

*** Doutorado em Letras pela Universidade Estadual Paulista Júlio de Mesquita Filho (2004). Atualmente, é Professora Assistente Doutora da Universidade Estadual Paulista Júlio de Mesquita Filho (FCL - UNESP/Assis), Atua no programa de pós-graduação PROFLETRAS - UNESP e integra os Grupos de Pesquisa: Teletandem: Transculturalidade das interações online via webcam e Grupo de Estudos e Pesquisas sobre Linguagem, Ensino e Narrativa de Professores..Email: kellychp@gmail.com
} 
elaborar propostas didáticas para o ensino de línguas, neste caso e mais especificamente, no ensino de língua espanhola.

A pesquisa foi desenvolvida no contexto das atividades do projeto de extensão Centro de Línguas e Desenvolvimento de Professores - CLDP $^{1}$ e do PIBID ${ }^{2}$. No CLDP, os alunos em formação inicial têm a oportunidade de ministrarem as aulas de língua espanhola para a comunidade externa, sob a supervisão de docentes da universidade, como parte de seus estágios. No PIBID, Subprojeto Letras/Espanhol, os alunos da graduação em Letras participam das aulas de língua espanhola no contexto de um Centro de Ensino de Línguas, sediado em uma escola pública da cidade. Tais contextos, portanto, possibilitaram o desenvolvimento da investigação e a participação do aluno bolsista na elaboração e aplicação das propostas, bem como na organização e análise dos materiais coletados.

Entre os objetivos da pesquisa, estavam previstos os seguintes: discutir sobre a natureza das propostas didáticas a partir da perspectiva teórica adotada; refletir sobre os critérios que devem ser considerados para: seleção, análise, adaptação e elaboração de materiais didáticos para o ensino de línguas estrangeiras, aqui mais especificamente, para o ensino do espanhol/LE; produzir e organizar propostas didáticas a serem utilizadas em seus diferentes contextos no ensino de línguas. Dessa forma, temos como objetivo mais amplo, contribuir para a formação crítico-reflexiva de professores de línguas, bem como para o estudo do processo de ensino e aprendizagem de línguas, mais especificamente de espanhol/LE.

Para subsidiar a investigação e o desenvolvimento das propostas didáticas, nos respaldamos teoricamente na perspectiva dos multiletramentos (ROJO e MOURA, 2012), que prevê, ao mesmo tempo, considerar a multiplicidade cultural das populações e a multiplicidade semiótica e multimodal dos textos, que em muito caracterizam as sociedades urbanas, atualmente (ROJO, 2012, p. 13). Também tomamos como referência as orientações previstas para a elaboração de materiais didáticos de Barros e Costa (2010), no capítulo 5 da Coleção Explorando o Ensino - Espanhol.

As perguntas que nortearam a pesquisa, por sua vez, foram assim estabelecidas: Como elaborar e organizar propostas didáticas para o ensino de língua espanhola? $\mathrm{O}$ que caracteriza o conceito de "multiletramentos"? Como o uso de novas tecnologias os chamados "novos letramentos" podem ajudar no ensino e aprendizagem de espanhol? Como inserir no processo de ensino de línguas aspectos da vida social e cultural do aluno? Como elaborar estratégias que facilitem a adaptação de materiais didáticos no ensino de línguas? Evidentemente, por tratar-se de uma pesquisa de iniciação científica, não foi possível explorar todas as questões com profundidade, mas buscamos nos orientar sempre por elas, ao longo do projeto.

Metodologicamente, o estudo foi orientado pela pesquisa de natureza qualitativa, de caráter interpretativista (LÜDKE; ANDRÉ, 1986), uma vez que há ênfase no processo, preocupação em se retratar a perspectiva dos participantes, além de o

\footnotetext{
${ }^{1}$ O Centro de Línguas e Desenvolvimento de Professores é um projeto de extensão colaborativo entre o Departamento de Letras Modernas e o Departamento de Educação da Faculdade de Ciências e Letras da UNESP/Assis, com o apoio da PROEX - Pró-Reitoria de Extensão UNESP. https://www.assis.unesp.br/\#!/extensao/legislacao/. Nesse contexto, alunos da graduação em Letras ministram cursos de idiomas à comunidade externa, com a supervisão dos docentes da UNESP.

${ }^{2}$ Programa Institucional de Bolsa de Iniciação à Docência, da CAPES. Edital no 61/2013. Esse subprojeto integrou o projeto PIBID UNESP (2014-2018). Nesse contexto, alunos da graduação em Letras Espanhol são inseridos na escola, onde podem acompanhar e auxiliar as atividades em sala de aula, com a supervisão dos professores da Educação Básica.
} 
ambiente natural constituir a fonte direta dos dados. Tais características enquadram-se aos nossos objetivos, uma vez que a pesquisa foi desenvolvida no contexto de um Centro de Línguas e Desenvolvimento de Professores e do PIBID, enfocando a formação inicial de professores, a produção de sua independência e o desenvolvimento de sua capacidade reflexiva. Nessa linha de pesquisa, o objetivo da relação pesquisador e professor não é só informar, mas produzir a independência e desenvolver a capacidade de reflexão desse último (TELLES, 2002). A metodologia qualitativa, portanto, além de permitir-nos observar todo movimento do processo pesquisado, caracteriza-se por esse caráter emancipador.

Após delinear esta breve contextualização da pesquisa, organizamos as próximas seções deste artigo da seguinte maneira: (I) breve apresentação do embasamento teórico; (II) discussão, análise e compartilhamento das propostas produzidas; (III) considerações finais.

\section{Discussão teórica}

Por meio da pesquisa bibliográfica, etapa inicial da investigação, apropriamonos de alguns conceitos teóricos os quais nortearam o desenvolvimento deste trabalho. Tais leituras propiciaram o conhecimento acerca de temas relevantes para a produção, análise e discussão das propostas didáticas, posteriormente.

O primeiro passo foi compreender a discussão que há em relação aos conceitos de alfabetização e letramento ${ }^{3}$. Num primeiro momento, observamos que era considerada apenas a condição de uma pessoa saber (ou não) ler e escrever, descrita como alfabetismo ou analfabetismo. Mais tarde, essa concepção se ampliou: com o avanço dos estudos na área, há uma "nova" compreensão de que não basta apenas ser alfabetizado, mas também ser letrado, ou seja, "saber também fazer o uso do ler e do escrever, saber responder às exigências da leitura e da escrita que a sociedade faz continuamente - daí o "recente" surgimento do termo letramento..." (SOARES, 2001, p. 20).

A respeito desse assunto, Baptista (2010) explica em seu texto "Traçando caminhos, letramento, letramento crítico e ensino de espanhol" que alfabetização corresponde ao domínio do código enquanto letramento remete ao exercício da própria escrita e pressupõe habilidades como ler e escrever; assim, letrar não significa apenas ensinar o ato da leitura e da escrita, mas a criar condições para que o sujeito se insira de maneira crítica e participativa dentro da sociedade. Dessa forma, o letramento escolar constitui uma prática social e configura, no ensino de línguas, a preocupação não somente com o aspecto formal como também a reflexão crítica e social.

No ensino da língua estrangeira, aqui no caso o espanhol, podemos aproximar os conteúdos à realidade do aluno e repensar o uso da língua para além das questões formais e estruturais. Sabemos que o espanhol, como língua de muitos países, é rico em sua multiculturalidade, o que oferece inúmeras possibilidades para o ensino e aprendizagem. Podemos pensar em formas de inserir o aluno ao contexto dos multiletramentos por meio das TICs, trabalhando com materiais autênticos, possibilitando o contato com os vários países latino-americanos, além da Espanha. Através de textos orais e escritos, vídeos e áudios (disponíveis na internet), é possível observar, analisar, questionar e debater diferentes pontos de vistas, nos quais o aluno possa construir sua própria compreensão e interpretação sobre temas da atualidade.

${ }^{3}$ Uma vez que, mais adiante, trataríamos do conceito de multiletramentos. 
De acordo com as OCEM (BRASIL, 2006, p. 148-149), a partir do contato ou do conhecimento com o a língua estrangeira e sua cultura, o aluno é levado a pensar o espanhol como um conjunto de valores e relações interculturais e, para que isso ocorra, é preciso que o ensino dessa nova língua adquira função social e contribua para a construção da cidadania. Assim, o estudante não será apenas um reprodutor de outro idioma, mas também uma pessoa crítica e reflexiva a respeito de si e do outro.

Segundo Barros e Costa (2010), é preciso "valorizar a heterogeneidade e a pluralidade da língua e desenvolver uma competência comunicativa e intercultural efetiva que permita ao aluno não só o aperfeiçoamento das habilidades linguísticas, mas também o contato com o outro e a reflexão sobre as diferenças culturais." Nesse caso, é necessário, além de oferecer aos alunos o conhecimento acerca do conteúdo com aspectos formais e gramaticais da língua, promover neles a formação humana e ética, abordando valores sociais, culturais, políticos e ideológicos preparando-os para a vida.

Antes de propor à classe uma atividade, é preciso que o professor acione o conhecimento prévio do aluno, ou seja, aborde primeiramente aquilo que ele já conhece para, a partir daí, ensinar algo novo. Essa forma de ensino e aprendizagem permite que o estudante relacione um conceito já existente a uma nova informação, que tenha sentido em sua vida e que não seja apenas um conhecimento isolado. Esse método remete ao que Baptista (2010) observa a respeito da abordagem sociocultural do letramento crítico, a qual "mobiliza outros conhecimentos e habilidades do sujeito além daqueles presentes nas dimensões linguísticas e psicolinguística” (p. 126). Segundo a autora, melhor que oferecer respostas definitivas e simplesmente expor atividades de leitura e escrita, é conduzir o aluno a uma visão crítica de textos, discursos e ideologias, enfatizando uma leitura reflexiva de modo a contribuir para a sua formação cidadã e sua inclusão no mundo letrado.

Sobre o conceito de multiletramentos, mais especificamente, observamos que foi "cunhado", segundo Rojo (2012), em 1996, por um grupo de pesquisadores dos letramentos em um Colóquio do Grupo de Nova Londres (GNL), em Londres. Esse grupo considerava uma pedagogia baseada em "futuros sociais" que abordaria a multiplicidade de culturas presentes em sala de aula e as novas Tecnologias de Informação e Comunicação (TIC); para tanto, criaram o termo "multiletramentos".

Os multiletramentos abordam dois tipos de multiplicidade presentes na nossa sociedade: "a multiplicidade cultural das populações e a multiplicidade semiótica de constituição de textos por meio dos quais ela se informa e comunica" (ROJO, 2012, p. 13). A autora explica que a multiplicidade de culturas configura "produções culturais letradas em efetiva circulação social como um conjunto de textos híbridos de diferentes letramentos (vernaculares e dominantes), de diferentes campos (ditos popular/ de massa / erudito), desde sempre" (p. 13), enquanto a multiplicidade das linguagens se refere ao texto, seja ele qual for, independentemente do tipo - impresso, digital ou analógico cada um possui um composto de muitas linguagens, fato que os caracteriza como multimodais ou multissemióticos.

Com o objetivo de discutir sobre a natureza das propostas didáticas e refletir sobre os critérios que devem ser considerados para: seleção, análise, adaptação e elaboração de materiais didáticos para o ensino do espanhol/LE, utilizamos também, como aporte teórico, os capítulos da Coleção Explorando o Ensino (vol 16), mais especificamente o capítulo 5: Elaboração de materiais didáticos para o ensino de espanhol (BARROS e COSTA, 2010). Segundo os autores: 


\begin{abstract}
(...) considera-se material didático qualquer instrumento ou recurso (impresso, sonoro, visual etc.) que possa ser utilizado como meio para ensinar, aprender, praticar ou aprofundar algum conteúdo. Sendo assim, enquadram-se nessa definição não só os manuais mencionados acima, ou apostilas, folhas de exercícios, testes, provas, mas também livros em geral, dicionários, áudios, vídeos, jornais, revistas, textos diversos, músicas, jogos etc. Cada um desses instrumentos tem suas especificidades e cabe destacar que materiais tais como vídeos, histórias em quadrinhos, músicas etc. Só se caracterizam efetivamente como didáticos quando são usados com alguma finalidade pedagógica determinada pelo professor, o qual, na maior parte das vezes, prepara uma atividade para explorá-los. Além disso, a relevância e a utilidade de qualquer material didático dependem das características da disciplina e dos objetivos que se pretendem alcançar. Para um curso de língua estrangeira, por exemplo, recursos audiovisuais podem ser mais convenientes e produtivos em determinados momentos do que o livro didático. (BARROS e COSTA, 2010, p.88)
\end{abstract}

Numa perspectiva integrada aos encaminhamentos propostos pelas OCEM (2006), que destaca o papel educativo das línguas estrangeiras, esse capítulo apresenta os fundamentos teóricos e as pautas para preparar materiais que facilitem o desenvolvimento linguístico do aluno e, ao mesmo tempo, estimulem o pensamento crítico e contribuam para a formação do senso de cidadania e da autonomia intelectual (BARROS e COSTA, 2010, p. 87). Dessa forma, focaliza os seguintes aspectos na produção de materiais didáticos: a língua como prática social culturalmente relevante; a abordagem de temas que facultem não só o ensino e a aprendizagem do idioma para a comunicação, mas também o posicionamento crítico perante assuntos da atualidade; o desenvolvimento de competências e habilidades linguísticas de maneira integrada e contextualizada; o ensino da leitura e da escrita na perspectiva dos multiletramentos e dos gêneros discursivos; o uso de textos autênticos; e o respeito à diversidade linguística e cultural (BARROS e COSTA, 2010).

Com relação ao processo de ensino e aprendizagem de uma língua, acreditamos que tais elementos não mais podem estar ausentes, se almejamos, em coerência com as novas orientações, uma educação cidadã:

O processo de ensino e aprendizagem de uma língua [...] não pode estar desarticulado ou desvinculado da sociedade na qual está inserido e nem desconsiderar as ideologias e as estruturas de poder desse entorno. Daí a necessidade de desenvolver o espírito crítico e preparar os alunos para compreender discursos de diversas mídias e culturas, tendo em conta as finalidades e intencionalidades presentes nos mais diversos textos que circulam na sociedade. Esse procedimento supõe provocar e fomentar questionamentos quanto aos sentidos produzidos e as suas implicações para os alunos enquanto sujeitos sociais e, ainda, envolvê-los na construção dos diferentes significados para não se tornarem consumidores passivos das diferentes ideologias. (BAPTISTA, 2010, p.119)

Com base em tais pressupostos teóricos, passamos à fase da elaboração e desenvolvimento das propostas didáticas para o ensino de espanhol, nos contextos considerados.

\title{
3 Elaboração e desenvolvimento das propostas didáticas
}

De início, encontramos algumas dificuldades no desenvolvimento da pesquisa, pois em nenhum outro momento da formação inicial havíamos nos deparado com o 
desafio de elaborar propostas didáticas para contextos reais de ensino da língua estrangeira. Também se constituía um desafio pensar na produção de tais propostas, a partir dos princípios que aqui adotamos integrando-os à perspectiva dos multiletramentos.

Iniciamos a produção do trabalho com algumas dificuldades e dúvidas, as quais foram sendo sanadas ao longo do desenvolvimento do projeto. Apresentamos, a seguir, parte desta experiência: a primeira delas, quando iniciamos nossa participação na pesquisa; e outra que realizamos mais ao final do processo. A primeira foi vivenciada no contexto do PIBID e a segunda no CLDP.

Elaboramos uma primeira proposta didática baseada no tema Las prendas de vestir intitulada: ¿Somos lo que llevamos? O objetivo proposto foi, inicialmente, a ampliação lexical, mostrando várias peças de roupas e suas variações de uso em contextos latino-americanos e peninsular; propusemos em seguida, como desdobramento da atividade e com base no referencial teórico, um debate sobre o tema "somos o que vestimos?", partindo da exibição de uma propaganda em vídeo da Coca$\mathrm{Cola}^{4}$, que trata sobre a questão do preconceito estético e das seguintes questões: ¿Somos lo que vestimos? ¿Las prendas de vestir definen nuestra personalidad? ¿Se puede juzgar a alguien por la manera que se viste? ¿Sabéis que significa la palabra "prejuicio"? Essa foi a produção inicial: um debate oral para instigar e inferir o conhecimento dos alunos a respeito do tema.

A finalidade do vídeo foi estimular a reflexão dos alunos sobre a temática do preconceito social, de forma a proporcionar a sistematização e ampliação de seus conhecimentos na língua estrangeira. $\mathrm{O}$ uso do audiovisual, o trabalho com materiais autênticos, nesse caso a propaganda, pode proporcionar a ampliação de conhecimento do aprendiz, conforme assinala Rojo (2012, p.8):

\begin{abstract}
Trabalhar com multiletramentos pode ou não envolver (normalmente envolverá) o uso de novas tecnologias de comunicação e informação ("novos letramentos"), mas caracteriza-se como um trabalho que parte das culturas de referência do alunado (popular, local, de massa) e de gêneros, mídias e linguagens por eles conhecidos, para buscar um enfoque crítico, pluralista, ético e democrático - que envolva agência de textos/discursos que ampliem o repertório cultural na direção de outros letramentos, valorizados [...] ou desvalorizados $[\ldots]$
\end{abstract}

$\mathrm{O}$ vídeo se baseia na hipótese de que as pessoas julgam precipitadamente aos demais pela maneira de se vestir, sem conhecê-los, e, muitas vezes, têm uma impressão equivocada a respeito do outro. Propusemos o vídeo como recurso para completar as atividades antes trabalhadas sobre o vocabulário e promover a discussão, parte mais relevante neste processo.

Após a exibição do vídeo, ouvimos a canção Bienvenido, de Laura Pausini ${ }^{5}$, e em seguida, empreendemos uma discussão oral, em língua espanhola, relacionando o vídeo com a música e estimulando a reflexão sobre como se encontra nossa sociedade, hoje, em relação à questão do preconceito.

Aproximando ao contexto em que os alunos estão inseridos, essa discussão foi permeada pela temática do Bullying na escola. Eles contaram casos de alunos que sofreram essa prática, desconstruindo preconceitos, conforme nomeado no vídeo, e

\footnotetext{
4 Propaganda em vídeo da Coca Cola, intitulada "Derribemos los prejuicios" (https://www.youtube.com/watch?v=y10u_THQ7w0) <Acesso 28/10/2017>.

${ }^{5}$ https://www.youtube.com/watch?v=FoOkSaZErAc
} 
refletindo sobre essa questão social no âmbito escolar. É importante salientar que essa atividade foi ministrada na época em que estava no auge o jogo da "baleia azul".

O jogo baseava-se na relação entre os desafiantes (também chamados jogadores, ou participantes) e os curadores (ou chamados de administradores). O jogo envolvia uma série de tarefas dadas pelos curadores, as quais os jogadores deveriam completar, a cada dia; algumas delas envolviam automutilação, sendo a última etapa o suicídio. Pôde-se discutir bastante sobre o tema, compartilhamos experiências; tal proposta resultou em uma discussão bastante produtiva, uma vez que muitos alunos adolescentes da escola estavam envolvidos com tal jogo.

E, ao finalizar a discussão, analisamos a letra da canção Bienvenido, de Laura Pausini, que remete ao tema da liberdade: El tema, que quiere decir Bienvenido a las cosas más verdaderas, a las personas más auténticas y a la libertad de ser unos mismos. Como desfecho, houve o consenso geral entre os alunos de que não importa qual seja a religião, a etnia, a opção sexual, muito menos o modo de se vestir, somos todos bem-vindos! Finalizamos essa sequência de atividades com a produção de um texto escrito em espanhol pelo grupo, a partir das ideias discutidas, como forma de sistematizá-las. Por meio das atividades, debates e questionamentos realizados a partir da propaganda e da música nas aulas de espanhol/LE para o grupo especificado, foi possível observar a eficiência desses recursos que, nesse caso, passaram a ser fonte para a proposta didática.

Sendo assim, acreditamos que cabe aos professores proporcionarem a seus alunos o contato com variados gêneros, não apenas aqueles pertencentes ao seu entorno cultural, mas também os originados em outras culturas e mídias. No caso específico do aprendizado de uma língua estrangeira, ao utilizar gêneros como propagandas em vídeos e músicas (por meio das TICs), por exemplo, a compreensão dessa língua pode tornar-se mais significativa e de maior interesse. Nesse sentido, a experiência com o uso de músicas, vídeos, nas aulas de espanhol/LE possibilitou constatar que tais gêneros como recursos didáticos, de fato, contribuem para o ensino, tornando-o mais atraente e vinculado à realidade do aluno, além de poder gerar efeitos positivos no tocante às emoções e ao bem-estar, também pôde propiciar um melhor desenvolvimento dos estudantes na segunda língua e estimular a sua participação nas aulas.

A segunda proposta didática que apresentamos, a seguir, foi elaborada mais ao final do semestre, com um pouco mais de reflexão, portanto, como resultado de certo amadurecimento em relação às experiências anteriores. Abordamos o gênero literário, trabalhando um texto muito conhecido do escritor argentino Júlio Cortázar. A partir da perspectiva proposta, esta sequência também se iniciou com a reprodução de vários vídeos produzidos sobre as conhecidas Instrucciones para subir una escalera; partia de um texto literário e propunha ao final a elaboração de outro texto, nos mesmos moldes. Em seguida, desenvolvemos seis atividades, procurando abranger as habilidades de produção e compreensão oral e escrita na língua estrangeira, conforme apresentamos, a seguir:

$1^{\text {a }}$ Etapa - Reproduções de alguns vídeos que se baseiam no referido texto: análise, comentários, comparação e discussão. Nesta atividade de produção inicial, os alunos foram estimulados a comentar suas impressões a respeito do conteúdo e forma como o texto foi reproduzido em cada um dos vídeos: alguns estritamente descritivos, em forma de desenhos; outros em forma de games; outros construídos com imagens de diferentes tipos de escada... Seguem os links dos vídeos utilizados: 
https://www.youtube.com/watch?v=Q1EfXX5U_Hs (vídeo comum) https://www.youtube.com/watch?v=511yKAtb0Eg (game) https://www.youtube.com/watch?v=e7JGICjdgEY (vídeo) https://www.youtube.com/watch? $\mathrm{v}=\mathrm{jVk} 7 \mathrm{omFVobE}$ (desenho) https://www.youtube.com/watch?v=Rz4wzvDhyu0 (desenho) (áudio) http://www.youtube.com/watch?v=SmHaY1UQGX4\&feature=related

Após a exibição dos vídeos, os alunos foram discutindo sobre o título do texto, o que lhes chamou bastante atenção, uma vez que ele rompe com a expectativa por tratarse de um texto literário: instruções para subir uma escada? O que parece mais "chocante" é o fato de que, embora seja um texto literário, tem uma função referencial, daí a surpresa do leitor ao ler tais "instruções literárias". A partir daí, fomos trabalhando a questão do humor e da ironia, uma das características da escrita de Cortázar:

La introducción a este manual es una escultura de la rutina, narrada en segunda persona, hacia un ser convencional que vive sin sorpresas una vida dentro de una construcción de "ladrillos de cristal" que le impide ver y apreciar lo que está afuera, refiriéndose tanto a la belleza como a las miserias del mundo. Luego de este disparador, el humor y la ironía se entremezclan y potencian dando lugar a todo tipo de instructivos, entre otros, para llorar, para tener miedo, para subir una escalera, para dar cuerda a un reloj. Considero imposible que el lector no sonría mientras recuerda cómo actúa en esas situaciones, pese a que esto no será sorpresa para quienes gustan de su alucinante literatura, ya que Cortázar nos tiene por demás acostumbrados a esa invitación a la complicidad.(Soledad Arrieta) https://www.escritores.org/recursos-para-escritores/colaboraciones/4074-historias-decronopios-y-de-famas-de-la-ironia-a-la-cotidianidad

2a. Etapa: após a introdução inicial ao texto, por meio dos vídeos, apresentamos aos alunos o texto literário, utilizando os recursos impressos e novamente de áudio. Para conduzir e aprofundar sua leitura e interpretação, seguimos o seguinte roteiro de perguntas:

- ¿Cómo se define la escalera en el texto? ¿De qué elementos se compone? ¿Para qué se utiliza?

- ¿Con qué fines crees que se redactan normalmente instrucciones?

- ¿Estos tipos de instrucciones son de hecho necesarias?

- ¿Cuál es la función del texto?

- ¿Se trata de un texto literario? ¿Por qué?

$3^{\text {a }}$. Etapa: foi necessário, a partir deste momento, contextualizar o texto, a obra de Cortázar, com algumas informações, tais como as que seguem, com o intuito também de estimular os alunos à leitura de todo o livro:

- Historias de Cronopios y de Famas (1962): una recopilación de sesenta y cuatro relatos cortos repletos de sarcasmo e ironía que esconden entre sus líneas reflexiones filosóficas a través de un lenguaje sencillo y claro. Esta obra, fiel reflejo de la sociedad del momento - pero aplicable a todos los tiempos -, se encuentra dividida en cuatro partes: la primera de ellas, Manual de Instrucciones, es una ridiculización de situaciones cotidianas y repetitivas que nos obliga a reflexionar sobre actos que consideramos 
habituales y a los que normalmente, no ponemos atención.(https://www.escritores.org/recursos-para-

escritores/colaboraciones/4074-historias-de-cronopios-y-de-famas-de-laironia-a-la-cotidianidad)

4a . Etapa: apresentação do autor e sua obra. Após apresentar elementos e informações sobre a obra completa, introduzimos informações a respeito da biografia de Julio Cortázar, enfatizando sua importância como representante da literatura argentina. Para tanto, propusemos a seguinte atividade, extraída de um material também disponível na internet: (file:///D:/Downloads/scenariusz-lekcji_instrucciones-para-subir-unaescalera_de-julio_cortazar.pdf)

Julio Cortázar está considerado como uno de los mejores y más importantes escritores de la lengua hispana. ¿Has oído hablar de él? ¿Has leído alguno de sus libros? Te presentamos a continuación unas fotografías con momentos de su vida. Haz hipótesis con tu compañero sobre cómo pudo ser su vida: dónde vivió, con quién, etc.
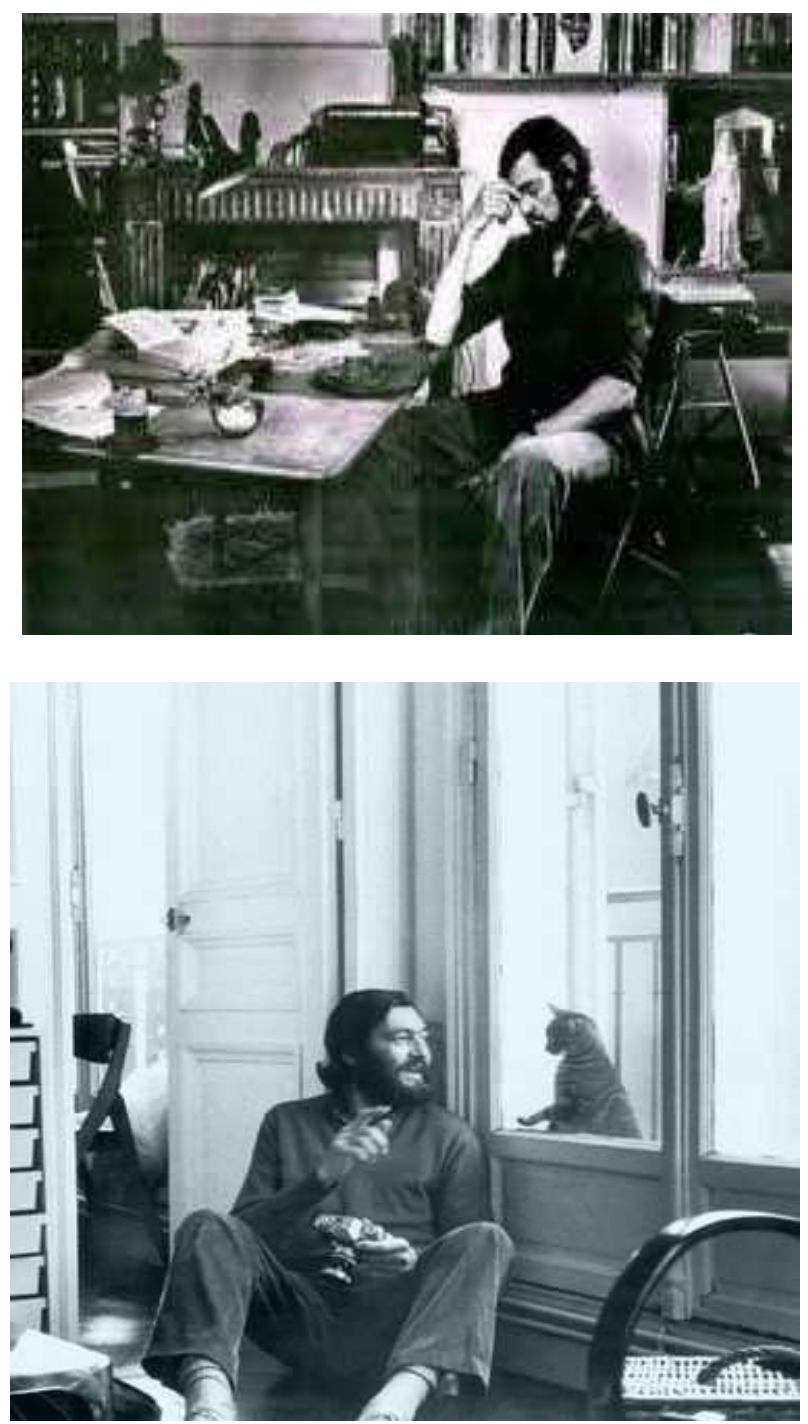


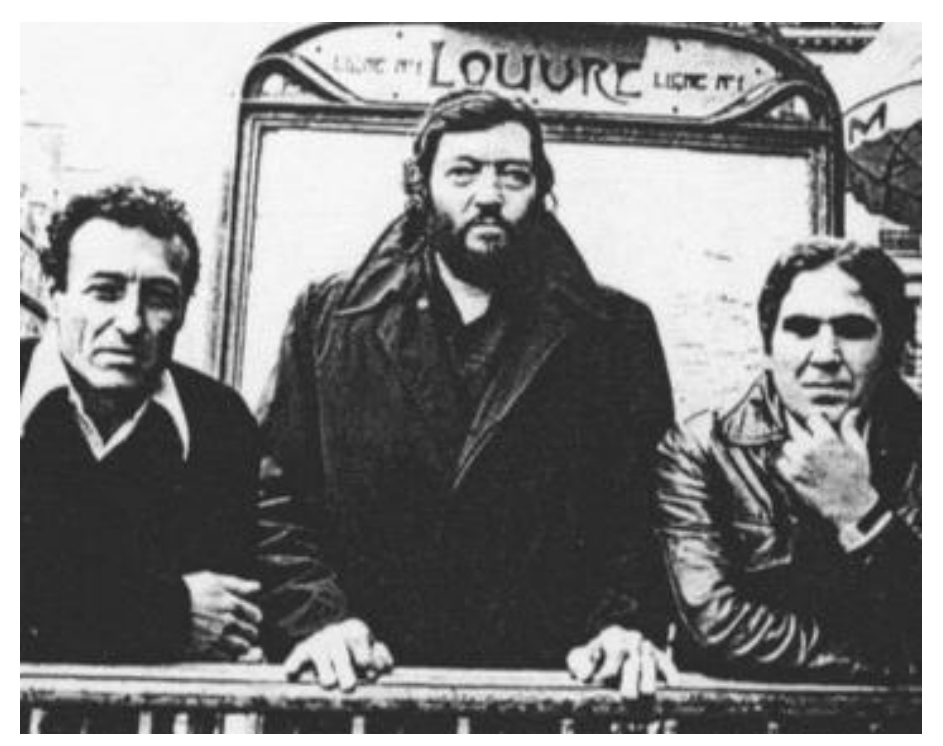

A continuación, busca con tu compañero en los siguientes enlaces algunos datos sobre su vida y obra y elabora con ellos una pequeña biografía.

- http://www.juliocortazar.com.ar <Acesso 28/10/2017>

- http://www.me.gov.ar/efeme/cortazar/index.html <Acesso 28/10/2017>

- http://www.epdlp.com/escritor.php?id=1607 <Acesso 28/10/2017>

$5^{\text {a }}$. Etapa: finalmente, propusemos algumas reflexões sobre aspectos linguísticos, mais especificamente o modo imperativo, com a seguinte atividade. Posteriormente à atividade, sistematizamos o uso e a conjugação dos verbos no modo imperativo.

- Habrás observado que estas instrucciones se dan de una forma impersonal. Cuando damos instrucciones también podemos utilizar el imperativo. A continuación, tienes las mismas instrucciones que se han dado en el texto pero formuladas con el imperativo y con un lenguaje un poco más simple. Busca en el texto sus equivalentes. Ejemplos: Sube las escaleras de frente. Mantente de pie, con los brazos colgando, levanta la cabeza sin que los ojos dejen de ver los peldaños superiores al que se pisa y respira lenta y regularmente.

6 . Etapa: Como atividade de produção final, dividimos a classe em grupos e sugerimos duas propostas, entre as quais eles poderiam escolher como avaliação final. Foram as seguintes:

- Produção de um texto escrito semelhante ao de Cortázar com base em outras instruções: para rir, para dormir etc...

- Produção de um vídeo sobre o texto de Cortázar ou sobre o texto produzido. (em grupos)

Destacamos que o desenvolvimento de toda a proposta didática apresentada resultou, ainda, ao final, em um debate bastante profícuo sobre a questão da acessibilidade (ou falta dela) nos espaços públicos, problemática que vivenciamos em nosso contexto. De todas as atividades, talvez seja esta a que mais possibilitou uma 
reflexão mais aprofundada sobre questões que extrapolam o conhecimento linguístico e a sala de aula.

Com o objetivo de arquivar e compartilhar as atividades planejadas e desenvolvidas, nos contextos mencionados, criamos uma plataforma online ${ }^{6}$, vinculada ao Centro de Línguas e Desenvolvimento de Professores - CLDP UNESP/Assis e ao Subprojeto PIBID/Espanhol UNESP/Assis. Além de um repositório, tal espaço virtual contribuiu especialmente para o compartilhamento das propostas didáticas com demais professores de espanhol/LE.

As propostas didáticas desenvolvidas durante o desenvolvimento da pesquisa se encontram disponíveis no link:

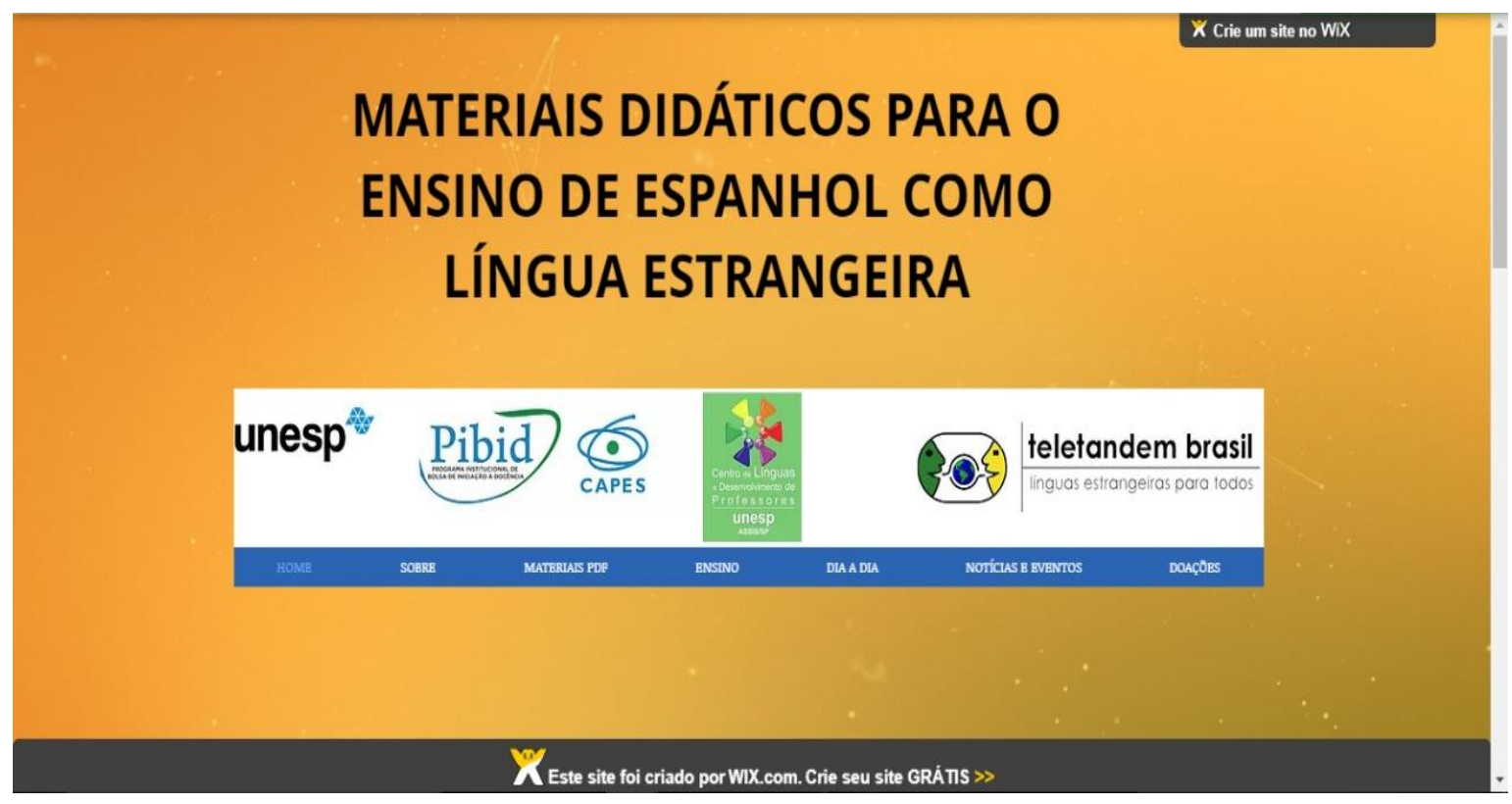

https://materialesespanhol.wixsite.com/cldp <Acesso 28/10/2017>

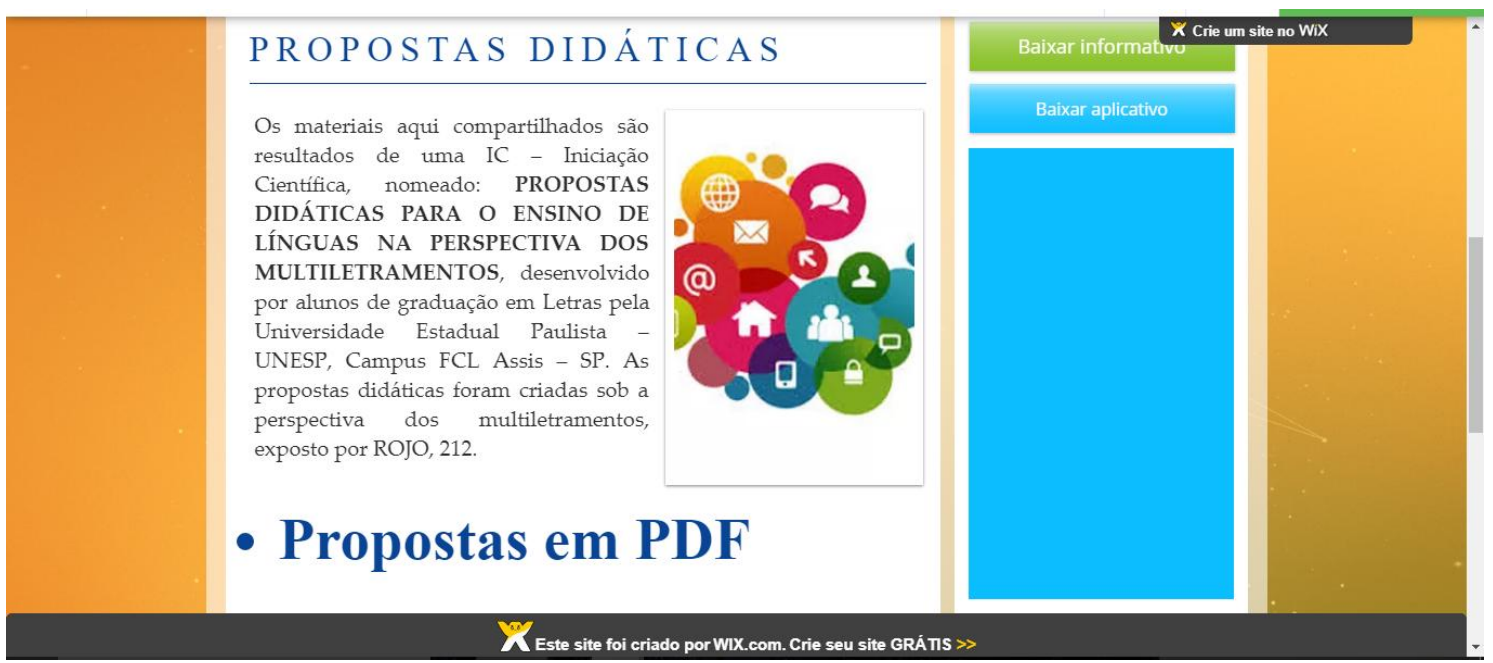

https://materialesespanhol.wixsite.com/cldp <Acesso 28/10/2017>

\footnotetext{
${ }^{6}$ Para a criação da plataforma, utilizamos um recurso gratuito e de fácil acesso, Wix.com. Wix.com é uma plataforma online de criação e edição de sites, que permite aos usuários criar sites em HTML5 e sites Mobile.
} 


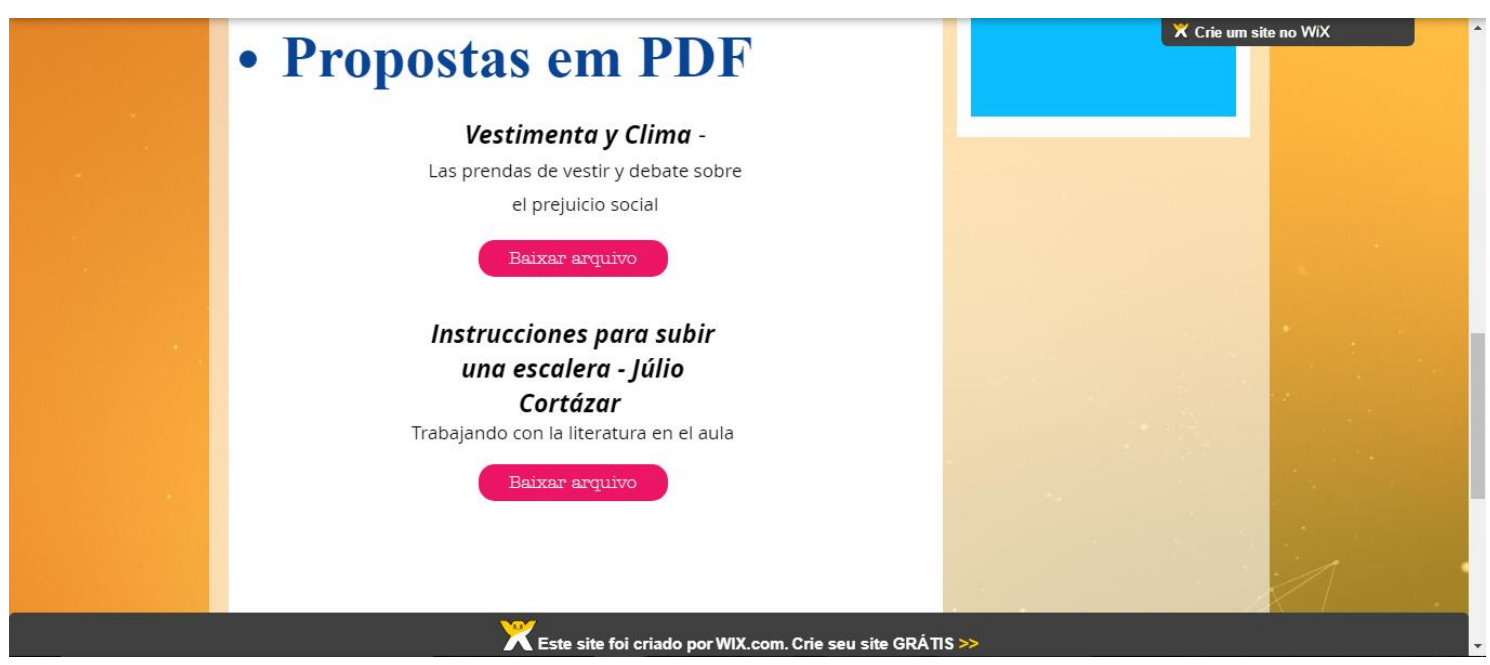

https://materialesespanhol.wixsite.com/cldp <Acesso 28/10/2017>

\section{Considerações Finais}

Neste trabalho, apresentamos parte das reflexões resultantes do desenvolvimento e orientação de um projeto de pesquisa de iniciação científica, realizado no contexto do CLDP e PIBID. Nesses espaços, os alunos envolvidos puderam vivenciar a atividade docente, ministrando cursos de língua espanhola e participando de aulas (no caso do PIBID). A pesquisa, conforme pontuamos, baseou-se nos seguintes objetivos: discutir sobre a natureza das propostas didáticas a partir da perspectiva dos multiletramentos; refletir sobre os critérios que devem ser considerados para: seleção, análise, adaptação e elaboração de propostas didáticas para o ensino de espanhol/LE; produzir e organizar propostas didáticas para os contextos considerados.

Com base nos resultados apresentados, podemos afirmar que a participação dos alunos envolvidos no desenvolvimento da pesquisa pôde contribuir significativamente para sua formação como professores de língua espanhola, conforme afirmam: "após o início da pesquisa, das leituras e fichamentos, passamos a refletir e a ter outro olhar sobre a prática docente, utilizando a tecnologia e variados recursos a favor do ensino e aprendizagem de LE".

A experiência de elaborar suas próprias propostas didáticas, refletir sobre elas e desenvolvê-las em um contexto de aula autêntico possibilitou-lhes um maior entendimento acerca desse processo tão complexo do saber docente. Com base no referencial teórico, as propostas didáticas foram construídas não apenas a partir de conteúdos gramaticais, mas, sobretudo, com o objetivo de promover a reflexão crítica diante de assuntos da atualidade e de interesse dos participantes; de sua cultura, portanto. Também foram utilizados diferentes gêneros, disponíveis na rede, o que possibilitou, de certo modo, promover os multiletramentos.

Acreditamos, que essa modalidade de pesquisa, co-construída no processo de observar, analisar, compartilhar e discutir sobre a natureza de propostas didáticas, a partir das experiências em atividades de docência pode auxiliar alunos (em processo de formação) na conscientização de suas dificuldades, assim como na compreensão dos processos de reflexão sobre a práxis docente e sua importância para a efetivação de contextos significativos de ensino e aprendizagem de línguas. 
Essa postura é essencial para uma formação mais sólida e propiciadora de autonomia, e, em decorrência, responsável por suas práticas futuras como profissionais críticos e reflexivos.

\section{Referências}

BRASIL. Orientações Curriculares para o Ensino Médio. Conhecimentos de Espanhol. Secretaria de Educação Básica. Brasília: Ministério de Educação, 2006.

BAPTISTA, L. M. T. R. Traçando caminhos: letramento, letramento crítico e ensino de espanhol. In: BARROS, C. S.; COSTA, E. G. M. (Coords.). Espanhol: Ensino Médio. Brasília: Ministério da Educação/Secretaria da Educação Básica, 2010. (coleção Explorando o Ensino, v.16).

BARROS, C. S.; COSTA, E. G. M. Elaboração de materiais didáticos para o ensino de espanhol. In: BARROS, C. S.; COSTA, E. G. M. (Coords.). Espanhol: Ensino Médio. Brasília: Ministério da Educação/Secretaria da Educação Básica, 2010. (coleção Explorando o Ensino, v.16).

LÜDKE, M.; ANDRÉ, M. E. D. A. Pesquisa em educação: abordagens qualitativas. São Paulo: E.P.U, 1986.

ROJO, R.; MOURA, E. (Orgs.). Multiletramentos na escola. São Paulo: Parábola, 2012. ROJO, R. Pedagogia dos multiletramentos: diversidade cultural e de linguagens na escola. In: Multiletramentos na escola. São Paulo: Parábola, 2012.

SOARES, Magda. Letramento: um tema em três gêneros. Belo Horizonte: Autêntica, 2001.

TELLES, J. A. “É pesquisa, é? Ah, não quero não, bem!” Sobre pesquisa acadêmica e sua relação com a prática do professor de línguas. Linguagem e ensino, vol.5, no. 2, 2002, p.91-116.

Recebido em 20 de fevereiro de 2019

Aceito em 06 de maio de 2019 